\title{
Comparison of effects of propofol and ketofol (Ketamine-Propofol mixture) on emergence agitation in children undergoing tonsillectomy
}

\author{
Saeed Jalili ${ }^{1}$, Ali Esmaeeili ${ }^{2}$, Koorosh Kamali ${ }^{3}$, Vahideh Rashtchi ${ }^{4}$
}

1. Anesthesiologist, Assistant Professor of Anesthesiology, Department of Anesthesiology, School of Medicine, Zanjan University of Medical Sciences, Zanjan, Iran.

2. Anesthesiologist, Department of Anesthesiology,Zanjan University of Medical Sciences, Zanjan, Iran.

3. PhD, Associate Professor of Epidemiology, Department of Public Health, School of Public Health, Zanjan University of Medical Sciences, Zanjan, Iran.

4. Anesthesiologist, Assistant Professor of Anesthesiology, Department of Anesthesiology, School of Nursing and Midwifery, Zanjan University of Medical Sciences, Zanjan, Iran.

\begin{abstract}
Background: The aim of this study was to compare the effect of propofol and ketofol (ketamine-propofol mixture) on EA in children undergoing tonsillectomy.

Method: In this randomized clinical trial, 87 ASA class I and II patients, aged 3-12 years, who underwent tonsillectomy, were divided into two groups to receive either propofol $100 \mu \mathrm{g} / \mathrm{kg} / \mathrm{min}$ (group $\mathrm{p}, \mathrm{n}=44$ ) or ketofol : ketamine $25 \mu \mathrm{g} / \mathrm{kg} / \mathrm{min}+$ propofol $75 \mu \mathrm{g} / \mathrm{kg} / \mathrm{min}$ (group k, n= 43). Incidence and severity of EA was evaluated using the Pediatric Anesthesia Emergence Delirium (PAED) scales on arrival at the recovery room, and 10 and 30 min after that time.

Results: There was no statistically significant difference in demographic data between the two groups. In the ketofol group, the need for agitation treatment and also mean recovery duration were lower than in the propofol group (30 and 41\%, and 29.9 and $32.7 \mathrm{~min}$ ), without statistically significant difference $(P$ value $=0.143$ and $P$ value $=0.187$ ). Laryngospasm or bronchospasm occurred in 2 patients in each group and bleeding was observed in only one individual in the ketofol group.

Conclusion: Infusion of ketofol in children undergoing tonsillectomy provides shorter recovery time and lower incidence of EA despite the non significant difference with propofol.
\end{abstract}

Keywords: Emergence agitation, ketofol, propofol.

DOI: https://dx.doi.org/10.4314/ahs.v19i1.50

Cite as: Jalili S, Esmaeeili A, Kamali K, V R. Comparison of effects of propofol and ketofol (Ketamine-Propofol mixture) on emergence agitation in children undergoing tonsillectomy. Afri Health Sci. 2019;19(1). 1736-1744. https:// dx.doi. org/10.4314/ abs. v19i1.50

\section{Introduction}

Emergence agitation (EA) was first described by Eckenhoff in the 1960s and is a condition that can occur during
Corresponding author:
Vahideh Rashtchi,
Department of Anesthesiology,
Zanjan University of Medical Sciences,
Mahdaviavenue, Zanjan,
45139-56184, Iran.
Email: Vrashtchi@gmail.com

emergence from general anesthesia. EA in children is characterized by confusion, irritability, inconsolable crying, disorientation and uncooperative state which may be associated with a number of causes including anxiety or agitation on induction, rapid awakening in an unfamiliar environment, separation from parents, psychological compromise, pain, airway obstruction, type and site of operation, pre-medication, technique of anesthesia and anesthetics side effects ${ }^{1-7}$. Post-operative pain is a major risk factor for EA. Several studies have shown that the incidence of EA decreased after adequate pain control but not eliminated ${ }^{3}$. Although, EA is usually self-limited and 
occurs within the first $30 \mathrm{~min}$ of stay in post anesthesia care unit, it may last up to 2 days. It can lead to physical damage, disconnection of monitoring devices or intravenous catheters, increase in the risk of bleeding, falling and self-extubation ${ }^{8,9}$. The incidence of EA varies from 10 to $80 \%$ and patients at high risk of EA are children aged $2-5$ years undergoing ENT procedures ${ }^{3-5}$. The feeling of suffocation in ENT procedures may be responsible for the event ${ }^{10}$. Many strategies have been previously used effectively to reduce the severity and incidence of EA, which include change in the technique of maintenance of anesthesia and administration of sedative and analgesic medications such as fentanyl, clonidine, dexmedetomidine, midazolam and ketamine before induction or at the end of surgery ${ }^{11,12}$.

Propofol is a sedative-hypnotic agent with rapid onset and short duration of action, which provides rapid awaking, with antiemetic property and used for induction and maintenance of general anesthesia. It has been shown that when propofol is used for maintenance of anesthesia, it reduces the incidence of $\mathrm{EA}^{13-18}$. Ketamine is a phencyclidine derivate with analgesic and amnestic effects $^{19-21}$. Both drugs: propofol and ketamine have been used successfully to control EA ${ }^{11,15,22}$.

Clinical effects of propofol and ketamine are complementary. When these agents are administered in combination, their doses decrease and unwanted effects are minimized $^{23}$. Ketofol, a mixture of ketamine and propofol reduces the sedative effect of propofol with lower toxicity as compared to each drug by reduction in the required doses ${ }^{20}$.

A number of studies have reported that ketofol is effective in pediatric procedural sedation including closed fractures reduction, suturing, foreign body removal, chest tube insertion, incision and drainage of abdominal wall abscess $^{24-29}$.

There is no research on the comparison of propofol and ketofol infusion as a total intravenous anesthesia (TIVA) on incidence of EA. So, the aim of this study was to compare the effect of TIVA with propofol versus ketofol (1:4 ratio) on incidence of emergence agitation in children undergoing tonsillectomy.

\section{Materials and methods}

This randomized controlled clinical trial was registered in IRCT (Iranian Registry of Clinical Trials) with registra- tion number 2017082829414N3. After approval by the Ethics Committee of Zanjan University of Medical Sciences and obtaining written informed consent from parents, this study was conducted on 87 children in Valiasr Hospital of Zanjan, Iran from November 2017 to March 2018.

All the children were in fasting state for $8 \mathrm{~h}$. On arrival at the operating room, standard anesthetic monitoring including non-invasive blood pressure, electrocardiogram and pulse oximeter were applied. After providing intravenous access, Ringer',s solution infusion was started. All the patients were pre-medicated with $1 \mu \mathrm{g} / \mathrm{kg}$ fentanyl and $0.02 \mathrm{mg} / \mathrm{kg}$ atropine. After $3 \mathrm{~min}$ of pre-oxygenation, general anesthesia was induced by $5 \mathrm{mg} / \mathrm{kg}$ sodium thiopental and $0.5 \mathrm{mg} / \mathrm{kg}$ atracurium, and after $3 \mathrm{~min}$, the nasal intubation with a proper spiral tube was performed. Mechanical ventilation was performed to maintain the ET-CO ${ }_{2}$ between 30-35 mmh. Maintenance of anesthesia was done using nitrous oxide/oxygen (50\%/50\%) and infusion of propofol or ketofol. Randomization was performed by random blocks ( $n=4)$.

The study was performed as a double blind clinical trial and the patients as well as anesthesiologists in the operating and recovery rooms were blinded to the agents administered. The anesthesiologist who administered the drugs and assessed the parameters was blinded to the study drugs because the drugs were prepared by a separate assistant who was not involved in the study, and the color and shape of the prepared drugs were the same.

1:4 ratio was chosen for ketofol infusion for maintenance of anesthesia during tonsillectomy which was associated with lower emergence agitation, hemodynamic instability and recovery time in previous studies ${ }^{30,31}$. A ketamine/ propofol admixture and propofol infusion was prepared by an assistant who was not involved in the clinical management of the study patients. Ketofol was prepared by mixing $40 \mathrm{mg}$ of ketamine $+160 \mathrm{mg}$ of Propofol 1\% in a $20 \mathrm{ml}$ syringe (the ratio of 1:4) and propofol by 20 cc propofol 1\% (200 mg) in another $20 \mathrm{ml}$ syringe. The initial maintenance infusion was started with the rate of $100 \mu \mathrm{g} / \mathrm{kg} / \mathrm{min}$ (or $0.6 \mathrm{ml} / \mathrm{kg} / \mathrm{h}$ ) in both groups. Both propofol and ketofol were administered with infusion pumps and their amounts were changed based on the patient's condition including heart rate and blood pressure. The dose of ketofol or propofol was adjusted to maintain heart rate and blood pressure within $20 \%$ of the prein- 
duction values. At the end of surgery and after discontinuation of the anesthetics, the patients received $0.04 \mathrm{mg} /$ $\mathrm{kg}$ neostigmine and $0.02 \mathrm{mg} / \mathrm{kg}$ atropine for reversal of the neuromuscular blockade. The nasotracheal tube was removed when spontaneous regular breathing was confirmed. Children were transferred to the Post Anesthesia Care Unit (PACU) and one of the parents accompanied them until discharge. In the PACU, respiratory rate and peripheral oxygen saturation $\left(\mathrm{SpO}_{2}\right)$ were recorded every $5 \mathrm{~min}$, but blood pressure was not measured to avoid physical stimulation.

During PACU, an anesthesiologist, who was blinded to the treatment allocation, evaluated the incidence and severity of EA using the Pediatric Anesthesia Emergence Delirium (PAED) scales which was developed by Sikich et $\mathrm{al}^{32}$ (Table 1). "Currently, the PAED scale is recognized as the standard for diagnosing ED in children with a score of $>12$ yielding $100 \%$ sensitivity and $94.5 \%$ specificity for the diagnosis of $\mathrm{ED}^{133,34}$." "Then, the results of each item were converted into scores, summed up and considered as PAED score; the higher the score, the more agitated the child. A cutoff $\geq 12$ was considered as presence of EA"34.

PAED score and pulse rate were assessed on arrival at the recovery room, and at 10 and $30 \mathrm{~min}$ (or discharge time) after that time. If PAED score was $\geq 12$, patients received midazolam for sedation.

The patients with laryngospasm, bronchospasm or bleeding, and patients requiring sedative were determined. The recovery time was recorded in patient's admission form.

Extubation time was defined as the time interval between discontinuation of anesthesia and removal of nasotracheal tube, and recovery time was defined as the time from arrival at the PACU to discharge.

\section{Statistical analysis}

In this study, assignment of patients into two groups was done using block randomization. All continuous data were normally distributed (Shapiro-Wilk test). Data were analyzed using IBM SPSS Advanced Statistics version 20.0 (SPSS Inc., Chicago, IL). Numerical data were expressed as mean and standard deviation. Qualitative data were expressed as frequency and percentage. Chi-square test (Fisher's exact test) was used to examine the relationship between qualitative variables. For quantitative data, comparison between two groups was done using independent sample t-test. A p-value $<0.05$ was considered significant.

\section{Results}

The Consolidated Standards of Reporting Trials (CONSORT) guidance for reporting results was followed (Figure 1).

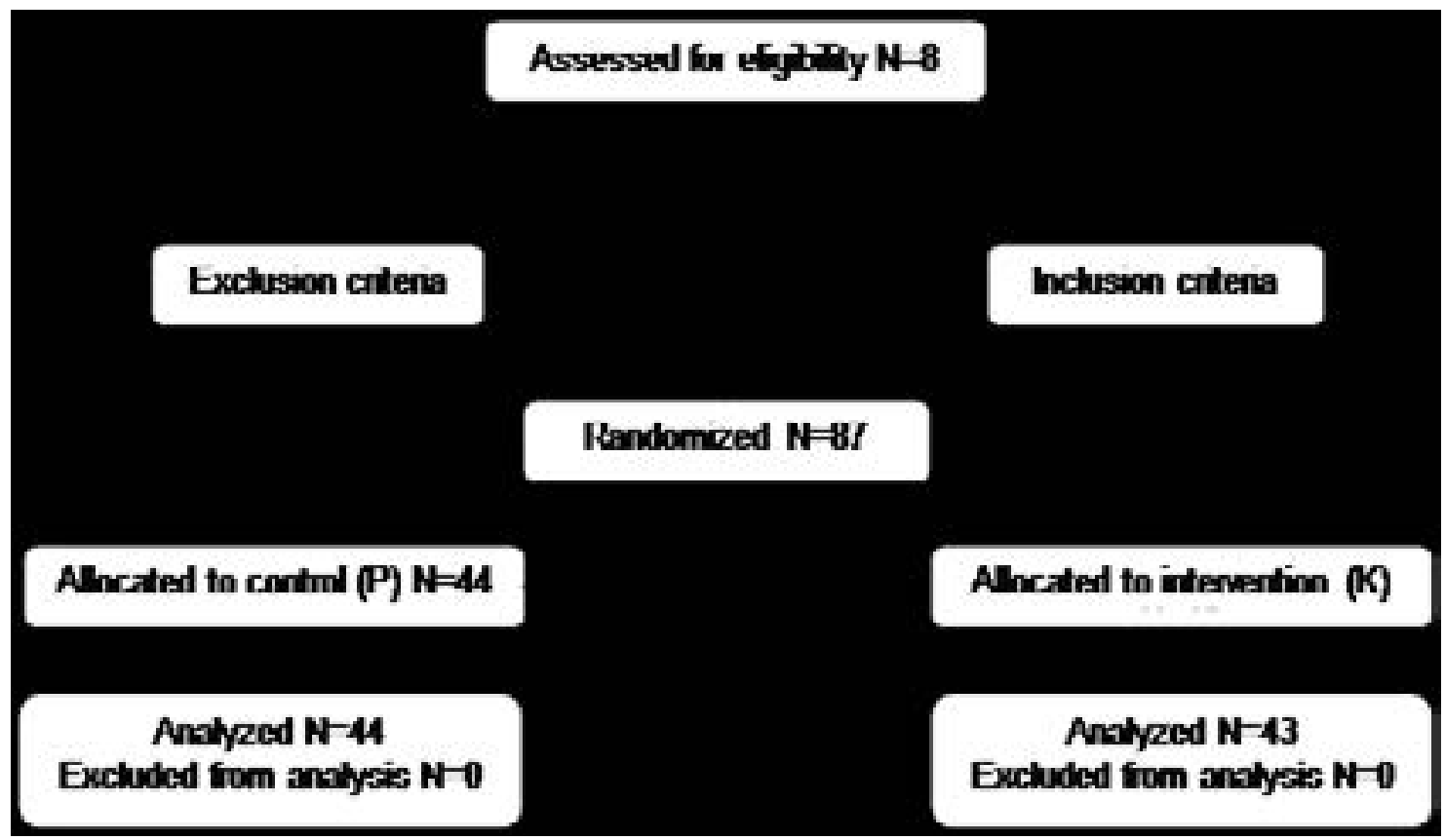

Figure1: CONSORT flow diagram 
In this study, a total of 87 patients were included, out of which, 44 were in the control group and 43 in intervention group. No patient was excluded from the study.
Demographic data including age and sex and also the duration of anesthesia in the two groups were similar and there was no statistically significant difference between these groups (Table 2).

Table 1: Pediatric Anesthesia Emergence Delirium (PAED) scales

\begin{tabular}{|c|c|c|c|c|c|c|}
\hline point & Description of items & Not at all & Just a little & Quite a bit & Very much & extremely \\
\hline 1 & $\begin{array}{l}\text { The child makes eye contact } \\
\text { with the caregiver }\end{array}$ & 4 & 3 & 2 & 1 & 0 \\
\hline 2 & $\begin{array}{l}\text { The child's actions are } \\
\text { purposeful }\end{array}$ & 4 & 3 & 2 & 1 & 0 \\
\hline 3 & $\begin{array}{l}\text { The child is aware of his/her } \\
\text { surroundings }\end{array}$ & 4 & 3 & 2 & 1 & 0 \\
\hline 4 & The child is restless & 0 & 1 & 2 & 3 & 4 \\
\hline 5 & The child is inconsolable & 0 & 1 & 2 & 3 & 4 \\
\hline
\end{tabular}

Table 2: Demographic data and duration of anesthesia in the two groups

\begin{tabular}{lccc}
\hline & Mean \pm SD & Mean \pm SD & P value \\
& Group K $(\mathrm{n}=43)$ & Group P $(\mathrm{n}=44)$ & \\
\hline Age(years) & $7.3 \pm 2.1$ & $7 \pm 2.1$ & 0.512 \\
$\begin{array}{l}\text { Durationof } \\
\text { anesthesia(min) }\end{array}$ & $29.4 \pm 7.5$ & $27.4 \pm 6.5$ & 0.190 \\
Male/Female * & $24 / 19$ & $20 / 24$ & 0.334 \\
\hline
\end{tabular}

*Data presented as male/female ratio.

PAED was used to monitor agitation on arrival at the recovery room, and at 10 and $30 \mathrm{~min}$ (or discharge time) after that time. As shown in Table 2 , there is no significant difference between the two groups in the incidence of agitation on arrival at the recovery room $(\mathrm{P}=0.058)$. Also, the incidence of agitation after 10 and 30 min stay in the recovery room showed no significant difference between the two groups $(\mathrm{P}=0.489$ and $\mathrm{P}=0.292)$.

During recovery, out of the 87 cases, 42 had PAED $\geq 12$, requiring therapy. Out of these, 15 cases $(35.7 \%)$ were in the intervention group and $27(64.3 \%)$ in the control group. When comparing the two groups, the difference was not significant $(\mathrm{P}=0.013)$ (Table 3). 
Table 3: incidence of EA based on PAED score

\begin{tabular}{|c|c|c|c|c|c|c|c|c|}
\hline \multirow{3}{*}{$\begin{array}{l}\text { Groups } \\
\text { Agitation } \\
(\text { PAED } \geq 12)\end{array}$} & \multicolumn{3}{|c|}{$\begin{array}{l}\text { On arrival at the } \\
\text { recoveryroom }\end{array}$} & \multicolumn{2}{|c|}{$\begin{array}{l}\text { after } 10 \text { min stay in the } \\
\text { recovery room }\end{array}$} & \multicolumn{3}{|c|}{$\begin{array}{l}\text { after } 30 \text { min stay in the } \\
\text { recovery room }\end{array}$} \\
\hline & Group K & Gro & $\mathrm{pP}$ & Group K & Group P & Group K & Gro & \\
\hline & $(\%)$ & $\mathrm{n}$ & $(\%)$ & $(\%)$ & $(\%)$ & $(\%)$ & $\mathrm{n}$ & $(\%)$ \\
\hline YES & 0 & 5 & 11.4 & 20.9 & $12 \quad 27.3$ & 14 & 10 & 22.8 \\
\hline No & 100 & 39 & 88.6 & 79.1 & $32 \quad 72.7$ & 37 & 34 & 77.2 \\
\hline P-value & \multicolumn{3}{|c|}{$0.058^{*}$} & \multicolumn{2}{|c|}{0.489} & \multicolumn{3}{|c|}{0.292} \\
\hline
\end{tabular}

*Fisher exact test $\mathrm{P}$ value

Regarding complications observed in the recovery room, 4 patients $(6.4 \%)$ had respiratory complications, out of which, 2 were $(5.4 \%)$ in the propofol group and two $(6.4 \%)$ in ketofol group. In the ketofol group, 3 patients $(7 \%)$ showed shivering and this was not seen in the propofol group. Also, in the ketofol group, 1 patient $(3.2 \%)$ showed tonsil bleeding without any case in the propofol group. The results showed that complications were not significantly different among the two groups ( $p$ value $=0.105)$.

Table 4: Anesthesia related parameters in the two groups

\begin{tabular}{lccc}
\hline & $\begin{array}{c}\text { Mean } \pm \text { SD } \\
\text { Group K }\end{array}$ & $\begin{array}{c}\text { Mean } \pm \text { SD } \\
\text { Group P }\end{array}$ & P Value \\
\hline Extubation time & $9.8 \pm 4.3$ & $9.6 \pm 4.3$ & 0.829 \\
Recovery time & $29.9 \pm 9.9$ & $32.8 \pm 10$ & 0.178 \\
Pulse rate before surgery & $116.7 \pm 19.1$ & $114.5 \pm 19$ & 0.597 \\
Pulse rate on arrival at the recovery room & $124 \pm 16.7$ & $124.1 \pm 16.5$ & 0.999 \\
Pulse Rate after 10 min stay in the recovery room & $113.4 \pm 14$ & $117 \pm 20.3$ & 0.331 \\
Pulse Rate after 30 min stay in the recovery room & $112.8 \pm 19.3$ & $116.4 \pm 20.3$ & 0.375 \\
\hline
\end{tabular}

Data are presented as mean and SD.

As shown in Table 4, extubation time was $9.8 \mathrm{~min}$ in the ketofol group and 9.6 min the in propofol group, with no statistically significant difference. Recovery time was $29.9 \mathrm{~min}$ in the ketofol group and $32.8 \mathrm{~min}$ in the propofol group, which is not statistically significant. Pulse rate before surgery, on arrival at the recovery room, as well as at 10 and $30 \mathrm{~min}$ after recovery were not significantly different in the two groups.

\section{Discussion}

The results of the current study showed that in all the stages, incidence of agitation in ketofol group was lower as compared to the control group, but this difference was not significant.

The recovery times were 29.9 and $32.8 \mathrm{~min}$ in ketofol and propofol groups, respectively, demonstrating that ketofol did not lead to longer recovery time. The results also showed that $35.7 \%$ patients in ketofol and $64.3 \%$ in propofol groups had $\mathrm{PAED} \geq 12$ which required therapy but the difference was not significant $(\mathrm{P}=0.013)$.

Both drugs: propofol and ketamine were used separately to control emergence agitation in adults and children. In 
a meta-analysis, propofol anesthesia was shown to cause a lower risk of EA than sevoflurane. The meta-analysis evaluated the incidence of EA in 14 trials with a total of 560 patients anesthetized with sevoflurane and 548 patients anesthetized with propofol, indicating that propofol anesthesia resulted in a lower incidence of $\mathrm{EA}^{35}$.

Another meta-analysis including non-randomized and randomized studies (158 studies, with more than 14,000 children) also reported a lower risk of ED with propofol when compared with sevoflurane ${ }^{36}$. Also, ketamine was shown to reduce the incidence of ED in children anesthetized with sevoflurane either after a bolus of $1 \mathrm{mg} / \mathrm{kg}$ IV followed by an infusion at $1 \mathrm{mg} / \mathrm{kg} / \mathrm{h}$, or as a single bolus of $0.25 \mathrm{mg} / \mathrm{kg}$ IV before the end of surgery ${ }^{36,37}$.

The results of Abu-Shahwan study showed that the addition of ketamine 10 min before the end of surgery significantly decreased the incidence of EA without delay in recovery time in children undergoing dental repair under general anesthesia with sevoflurane .A recent meta-analysis has shown that ketamine has a prophylactic effect in preventing sevoflurane-related $\mathrm{EA}^{38}$.

Post-operative pain has been a major confounding factor in the analysis of factors triggering the agitation. In several studies, the use of preemptive analgesia provided significant reduction in agitation. However, even when post-operative pain is treated effectively in patients undergoing general anesthesia, post-operative agitation may occur $^{39-42}$.

It was found that although, EA decreased in ketofol infusion group, its difference with propofol group was non-significant, and show similar results with previous studies $^{9,39,41,42}$.

Although, ketamine has powerful analgesic effect and also additive effects in combination with propofol, decrease in frequency of agitation in ketofol as compared to propofol alone was non-significant. Therefore, it seems analgesic and sedative effects of ketamine plus propofol could not provide more significant reduction of EA, at least in ketofol combination with ratio of 1:4.

However, the authors of the current study suggested that even this insignificant difference is likely to be more related to the additive sedative effects of ketamine and propofol than pure analgesic effect of ketamine, as suggested in other studies ${ }^{43}$.
It seems ketofol infusion in a ratio of 1:4 for 30 min does not lead to delayed recovery, probably, it may be due to the context-sensitive half-life of ketamine, which is known to increase dramatically after $30 \mathrm{~min}^{44}$, and also consistent with the results of Finn and colleague's study ${ }^{33}$.

Also, Akin concluded that the addition of ketamine to propofol preserved hemodynamic stability without prolonging recovery time or increasing the incidence of adverse events in pediatric patients undergoing cardiac catheterization $^{46}$. The results of these researches are also consistent with the present one.

Ketofol infusion is mainly used for sedation and analgesia in procedures ${ }^{24-29}$ and most researches have emphasized on its cardiovascular properties and short time recovery but to the authors' knowledge, no study has used it for maintenance of general anesthesia (as a TIVA) and evaluated EA risk reduction in children in the operating room; although, ketamine and propofol has been used separately for this purpose.

The ideal ketamine to propofol ratio for anesthesia remains unclear. The ratios of 1:2 and 1:1 were associated with high incidence of psychotropic effects (10\% unpleasant dreams) and ratios of 1:4 to1: 6.7 proved just as effective ${ }^{47}$. Several studies have used different ratios from $1: 1$ to $1: 10^{27,30}$. Coulter suggested that $1: 3$ is the optimum combination for bolus dosing and 1:4 is suitable for ketofol infusion ${ }^{48}$. In another study, the ratio of 1:3 was the best combination for intermittent dosing ${ }^{49}$.

Daabiss et al. used 1:4 ratio of ketamine to propofol for surgical procedure on 3-12 years old children and concluded that infusion with this proportion had adequate sedation and analgesic effects without hemodynamic and respiratory depression or psychotomimetic side effects ${ }^{32}$. Similarly, in the present study, TIVA with ketofol infusion (1:4 ratio) was not associated with hemodynamic instability, delayed extubation or recovery time, and major unexpected events.

A study conducted by Sherry et al. showed that ketofol as well as propofol were significantly effective in reducing the frequency of EA as compared to the control group. The lowest frequency was in favor of ketofol despite the non-significant difference with propofol. Ketofol demonstrated more analgesic effect during the immediate postoperative period. Adequate postoperative sedation and analgesia was accompanied by better recovery criteria and 
hemodynamic stability but the difference in frequency of emergence agitation was non-significant between propofol and ketofol groups, which is similar to results of the present study.However, unlike the present study, they used sevoflurane-based anesthesia for all the children and administered a single dose of propofol $(1 \mathrm{mg} / \mathrm{kg})$ or ketofol $(1 \mathrm{mg} / \mathrm{kg}$ propfol and $0.25 \mathrm{mg} / \mathrm{kg}$ ketamine $)$ at the end of adenotonsillectomy. Also, in the study of Sherry, the time to discharge from PACU was comparable in the three groups $(p=0.079)$ which is similar to the present study $^{50}$.

In the current study, the pulse rate showed no significant differences in the two groups. The reason is that cardiovascular effects of each drug are contrasting in action and balance each other out when combined.

Ketamine is sympathomimetic and can facilitate bleeding through increase in blood pressure even at low doses. In the current study, one case of bleeding occurred in the ketofol group; since ketamine was given to patient during surgery, and it was able to cause bleeding, the surgeon performed the necessary hemostasis. On the other hand, ketamine reduces agitation in recovery, thus reduces the hemodynamic changes in the recovery and protects against bleeding.

Comparison between different studies is difficult due to the lack of a uniform definition of EA and the lack of a universal assessment scale.These discrepancies could be due to the sample size, moment and methods of EA evaluation, different types of surgeries, the duration of follow-up, genetic variations and different responses to drugs; therefore, further studies on different types of surgeries are recommended.

There are some limitations to this study. First, the authors were unable to determine other causes of agitation in recovery. Furthermore, because the power of the study was $51 \%$ when compared with accepted percent of $80 \%$, more studies with more sample size or other proportion of ketofol are recommended.

\section{Conclusion}

In conclusion, infusion of ketofol for maintenance of anesthesia in children undergoing tonsillectomy provides relatively shorter recovery time, lower PAED score and hemodynamic stability in comparison with propofol administered alone for anesthesia, although with no significant difference.

\section{Conflict of interests}

The authors declare that there is no conflict of interest regarding the content of this article.

\section{References}

1- Voepel-Lewis T, Burke C, Hadden S.M, TaitA.R, Malviya S. Nurses' diagnoses and treatment decisions regarding care of the agitated child. J Perianesth Nurs. 2005; 20 (4): 239-248.

2- Akihiro Kanaya. Emergence agitation in children: risk factors, prevention, and treatment. J Anesth. 2016; 30:261-267. PubMed.

3- Nasar VG, Hannallah RS. Emergence agitation in children: a review. MEJ Anesth. 2011; 21(2):175-84. PubMed. 4- Beskow A, Westrin P. Sevoflurane causes more postoperative agitation in children than does halothane. ActaAnaesthesiol Scand. 1999; 43(5):536-41.

5- Hollister GR, Burn JM. Side effects of ketamine in pediatric anesthesia. AnesthAnalg. 1974; 53(2):264-7. PubMed.

6- De grood PM, Coenen LG, Van Egmond J, Booij LH, Crul JF. Propofol emulsion for induction and maintenance of anesthesia. A combined technique of general and regional aneshtsia. Acta Anaesthesiol Scand. 1987; 31:219-223. PubMed.

7- Abu-Shahwan I, Chowdary K. Ketamine is effective in decreasing the incidence of emergence agitation in children undergoing dental repair under sevoflurane general anesthesia. Paediatric Anaesthesia. 2007; 17(9):846-50.

8- Lepousé C, Lautner CA, Liu L, Gomis P, Leon A. Emergence delirium in adults in the post-anaesthesia care unit. Brit J Anaesth. 2006; 96 (6):747-753.

9- Mohkamkar M, Farhoudi F, Alam-Sahebpour A, et al. Postanesthetic Emergence Agitation in Pediatric Patients under General Anesthesia. Iran J Pediatr. 2014; 24(2):184190.

10- Vlajkovic GP, Sindjelic RP. Emergence delirium in children: many questions, few answers. Anesth Analg. 2007; 104(1):84-91.

11- Dahmani S, Delivet H, Hilly J. Emergence delirium in children: an update. Current Opinion in Anaesthesiology. 2014; 27(3):309-15.

12- Kim MS, Moon BE, Kim H, Lee JR. Comparison of propofol and fentanyl administered at the end of anaesthesia for prevention of emergence agitation after sevofluraneanaesthesia in children. British Journal of Anaesthesia. 2013; 110 (2):274-80. 
13- Cohen IT, Finkel JC, Hannallah RS et al. Rapid emergence does not explain agitation following sevofluraneanaesthesia in infants and children: a comparison with propofol. Paediatr Anaesth. 2003; 13:63-67.

14- Lope'z Gil ML, Brimacombe J, Clar B. Sevoflurane versus propofol for induction and maintenance of anaesthesia with the laryngeal mask airway in children. Paediatr Anaesth. 1999; 9:485-490.

15- Nakayama S, Furukawa H, Yanai H. Propofol reduces the incidence of emergence agitation in preschool-aged children as well as in school-aged children: a comparison with sevoflurane. J Anesth. 2007; 21:19- PubMed ;23.

16- Picard V, Dumont L, Pellegrini M. Quality of recovery in children: sevoflurane versus propofol. Acta Anaesthesiol Scand. 2000; 44:307-310.

17- Bahn EL, Holt KR. Procedural sedation and analgesia: a review and new concepts. Emergency Med Clin North Am. 2005; 23:503-517.

18- De grood PM, Coenen LG, Van Egmond J, Booij LH, Crul JF. Propofol emulsion for induction and maintenance of anesthesia. A combined technique of general and regional aneshtsia. Acta Anaesthesiol Scand. 1987; 31:219- PubMed ;223.

19- Green SM, Krauss B.The semantics of ketamine. Ann Emergency Med. 2000; 39:480-2. PubMed.

20- Camu F, Vanlersberghe C. Pharmacology of systemic analgesics. Best Pract Res ClinAnaesthesiol. 2002; 16:475-88. 21- Warncke T, Stubhaug A, et al. Ketamine, an NMDA receptor antagonist, suppresses spatial and temporal properties of burn induced secondary hyperalgesia in man: a double-blind, cross-over comparison with morphine and placebo. Pain. 1997; 72:99-106. PubMed.

22- Pieters BJ, Penn E, Nicklaus P, Bruegger D, Mehta B, Weatherly R. Emergence delirium and postoperative pain in children undergoing adenotonsillectomy: a comparison of propofolvssevoflurane anesthesia. Paediatric Anaesthesia. 2010; 20(10):944-50.

23- Okuyama K, Inomata S, Okubo N, Watanabe I. Pretreatment with small-dose ketamine reduces predicted effect-site concentration of propofol required for loss of consciousness and laryngeal mask airway insertion in women. J ClinAnesth. 2011; 23:113-118. PubMed.

24- Godambe SA, Elliot V, Matheny D, Pershad J. Comparison of propofol/fentanyl versus ketamine/midazolam for brief orthopedic procedural sedation in a pediat- ric emergency department. Pediatrics. 2003; 112:116-123. PubMed.

25- Sharieff GQ, Trocinski DR, Kanegaye JT, Fisher B, Harley JR. Ketamine-propofol combination sedation for fracture reduction in the pediatric emergency department. Pediatr Emergency Care. 2007; 23(12):881-884.

26- Shah A,Mosdossy G, McLeod S, Lehnhardt K, Peddle M, Rieder M. A blinded, randomized controlled trial to evaluate ketamine/propofol versus ketamine alone for procedural sedation in children. Ann Emergency Med. 2011; 57(5):425-433.

27- Andolfatto G, Willman E. A prospective case series of pediatric procedural sedation and analgesia in the emergency department using single-syringe ketaminepropofol combination (ketofol). Acad Emergency Med. 2010; 17 (2):194-201.

28- David H, Shipp J. Randomized controlled trial of ketamine/propofol versus propofol alone for emergency department procedural sedation. Ann Emergency Med. 2011; 57(5): 435.

29- Arora S. Combining ketamine and propofol ("ketofol") for emergency department procedural sedation and analgesia: a review. West J Emergency Med. 2008; 9(1):20-23. 30- Daabiss M, Elsherbiny M, AlOtibi R. Assessment of different concentrations of ketofol in procedural operation. BJMP. 2009; 2(1):27-31.

31- Wang Y, Jiang X, Pang L,et al. A randomized double-blind controlled study of the efficacy of ketofol with propofol-fentanyl and propofol alone in termination of pregnancy. Afr J pharm pharmacol. 2012; 6(34):2510-2514. 32- Sikich N, Lerman J. Development and psychometric evaluation of the pediatric anesthesia emergence delirium scale. Anesthesiology. 2004;100(5):1138-45.

33- Somaini M, Engelhardt T, Fumagalli R, Ingelmo PM. Emergence delirium or pain after anaesthesia--how to distinguish between the two in young children: a retrospective analysis of observational studies. $\mathrm{Br} J$ Anaesth. 2016; $116: 377$.

34- Bajwa SA, Costi D, Cyna AM. A comparison of emergence delirium scales following general anesthesia in children. Paediatr Anaesth. 2010; 20:704-11. PubMed.

35- Kanaya A, Kuratani N, Satoh D, Kurosawa S. Lower incidence of emergence agitation in children after propofol anesthesia compared with sevoflurane: a meta-analysis of randomized controlled trials. J Anesth. 2014; 28:4-11. PubMed. 
36- Costi D, Cyna AM, Ahmed S, et al. Effects of sevoflurane versus other general anaesthesia on emergence agitation in children. Cocbrane Database Syst Rev. 2014; :CD007084.

37- Dalens BJ, Pinard AM, Létourneau DR, et al. Prevention of emergence agitation after sevoflurane anesthesia for pediatric cerebral magnetic resonance imaging by small doses of ketamine or nalbuphine administered just before discontinuing anesthesia. Anesth Analg. 2006; 102:1056.

38- Dahmani S, Stany I, Brasher C,et al. Pharmacological Prevention of Sevoflurane- and Desflurane-Related Emergence Agitation in Children: A Meta-Analysis of Published Studies. British Journal of Anaesthesia. 2010; 104:216-223.

39- Silva LM, Braz LG, Módolo NS. Emergence agitation in pediatric anesthesia: current features. J Pediatr. (Rio J). 2008;84(2):107-13.

40- Davis PG, Greeberg JA, Genldeman M, Fertal K. Recovery characteristics of sevoflurane and halothane in preschool-aged children undergoing bilateral myringotomy and pressure equalization tube insertion. Anesth Analg. 1999; 88: 34-8. PubMed.

41- Isik B, M Arslan, Tunga AD, Kurtipec O. Dexmedetomidine decreases emergence agitation in pediatric pacientes after sevoflurane anesthesia without surgery. Paediatr Anaesth. 2006; 16: 748-53 PubMed.

42- Weldon BC, Bell M, T. Craddock. The effect of caudal analgesia on emergence agitation in children after sevoflurane versus halothane anesthesia. Anesth Analg. 2004; 98: 321-6. PubMed.

43- Hui TW, Short TG, Hong W, et al. Additive interactions between propofol and ketamine when used for anesthesia induction in female patients. Anesthesiology. 1995;82:641-648

44- Dallimore D, Anderson BJ, Short TG et al. Ketamine anesthesia in children-exploring infusion regimens. Pediatr Anesth. 2008; 18:708-714. PubMed.

45- Finn LS Coulter, Jacqueline A Hannam, Brian J Anderson. Ketofol dosingsimulations for procedural sedation. Pediatric Emergency Care . 2014; 30(9).

46- Akin A, Esmaoglu A, Guler G, Demircioglu R, Narin $\mathrm{N}$, Boyaci A. Propofol and propofol-ketamine in pediatric patients undergoing cardiac catheterization. PediatrCardiol. 2005; 26(5):553-7.

47- Tosun Z, Esmaoglu A, Coruh A. Propofol -ketamine vspropofol-fentanyl combinations for deep sedation and analgesia in pediatric patients undergoing burn dressing changes. PediatrAnesth. 2008; 18:43-47.

48- Coulter FLS, Hannam JA, Anderson BJ. Ketofol dosing simulations for procedural sedation. Pediatric Emergency Care. 2014; 30(9):621-30.

49- AmornyotinS. Ketofol: A Combination of Ketamine and Propofol. Journal of Anesthesia \& Critical Care. 2014; $1(15)$.

50- Sherry N, Riz k, Enas M, Samir. Use of ketofol to control emergence agitation in children undergoing adenotonsillectomy. Egyptian Journal of Anaesthesia. 2014; 30:13-19. 